\title{
CONCEPÇÕES TEÓRICAS E FILOSÓFICAS DO ABORTO DE ANENCÉFALO: ENTENDIMENTO DOS VOTOS DO SUPREMO TRIBUNAL FEDERAL
}

\author{
Gustavo Henrique Borges Polegati, Rachel Lopes Queiroz Chacur \\ Universidade do Oeste Paulista - UNOESTE. Curso de Direito, Presidente Prudente - SP. E-mail: \\ gupolegatti@hotmail.com
}

\section{RESUMO}

O presente projeto de pesquisa desenvolveu o debate sobre as controvérsias à respeito da recente decisão do Supremo Tribunal Federal, com enfoque na Arguição de Descumprimento de Preceito Fundamental 54 que tornou desnecessária a autorização judicial para o aborto, no caso de fetos anencéfalos. $O$ objetivo geral da pesquisa analisou os votos do Supremo Tribunal Federal sobre a autorização do aborto de anencéfalo. Os objetivos específicos abordaram a evolução histórica das decisões dos tribunais superiores, a lacuna na lei federal sobre o tema proposto, a conduta dos tutelados do direito, a conduta médica, a questão do procedimento adotado, a fiscalização do Estado, por meio da análise criteriosa de todos os votos do Supremo Tribunal Federal. A justificativa baseou-se na necessidade de especificar pela via legal ou jurisprudencial os critérios de viabilidade e procedimento à contento, dentro dos ditâmes lícitos e com segurança jurídica dos envolvidos no ato do abortamento. Os pesquisadores enfocaram com precisão a análise, na íntegra e literal, dos votos do Supremo Tribunal Federal sobre o Aborto de feto anencefálico. $O$ presente estudo foi desenvolvido pelo método hipotético-dedutivo, com os estudos de material bibliográfico, normas jurídicas, artigos jurídicos, leis, posicionamentos doutrinários e análise dos respectivos votos. Ao final, de forma suscinta, as conclusivas apresentam as medidas legais cabíveis de efetivação da decisão do Supremo Tribunal Federal, sem deixar margem à ilegalidade e contribuir para com a propostas de políticas públicas regulamentadoras para a efetivação material do aborto de feto anencefálico.

Palavra-chave: ABORTO, ANECÉFALO, SUPREMO TRIBUNAL FEDERAL

\section{HEORETICAL AND PHILOSOPHICAL CONCEPTS OF anencephalic ABORTION: UNDERSTANDING OF VOTES OF FEDERAL SUPREME COURT}

\begin{abstract}
This research project developed the debate on the controversies regarding the recent decision of the Supreme Court, focusing on the accusation of breach of Fundamental Precept 54 that made it unnecessary to judicial authorization for abortion in the case of anencephalic fetuses. The overall objective of the research examined the votes of the Supreme Court on the authorization of abortion anencéfalo. Os specific objectives addressed the historical evolution of the decisions of the higher courts, the gap in federal law on the theme, the conduct of the protected right, medical management, the question of the procedure adopted, the supervision of the State, through a careful analysis of all the votes of the Supreme Court. The rationale was based on the need to specify the legal or jurisprudential via the viability criteria and procedure to satisfaction with in the dictates lawful and legal security of those involved in the act of abortion. The researchers focused on the precise analysis, in full and literal, of the votes of the Supreme Court on Abortion anencephalic fetus. The present study was developed by the hypothetical-deductive method, with studies of bibliographical material, legal rules, legal articles, laws, doctrinal positions and analysis
\end{abstract}


of their votes. At the end of succinct manner, the concluding exhibit appropriate legal action to effect the decision of the Supreme Court, leaving no room for lawlessness and to contribute to the proposed regulatory policies for the material realization of the abortion of anencephalic fetus.

Keywords: ABORTION, ANECÉFALO, FEDERAL SUPREME COURT 


\section{INTRODUÇÃO}

A problemática da hipótese proposta se funda no reconhecimento do Direito de escolha da gestante em realizar o abortamento nesses casos. O Supremo Tribunal Federal, na Arguição de Descumprimento de Preceito Fundamental de número 54, julgou procedente o abortamento nos casos de anencefalia, reconhecendo direito de escolha da gestante, que poderá optar em realizar o abortamento ou não, sendo necessário apenas laudo médico simples. Não há mais necessidade de autorização judicial, basta apenas a autorização médica. No entanto, o debate enfoca a problemática do objeto da decisão do Supremo Tribunal Federal, a qual deixa à cargo do médico, fazer ou não o abortamento, sem nenhuma fiscalização do Estado, o que possivelmente enseja em abortamentos ilegais ou então no risco de ocorrer falso laudo médico e abortamento de fetos saudáveis. Os debates dos juristas e a sociedade abordam a segurança jurídica e o amadurecimento da cidadania em nosso país, para tamanho avanço de opção das gestantes, em um tema tão polêmico e complexo, quanto o Aborto.

\section{METODOLOGIA DA PESQUISA}

O objetivo geral analisou os votos do Supremo Tribunal Federal considerando a questão de agilidade do procedimento deixando à cargo do médico fazer ou não fazer o abortamento para o caso específico, levantando a hipótese de desvio da conduta com falsos laudos, na tentativa de realização abortos ilegais, sem nenhuma fiscalização do Estado, trazendo uma lacuna no texto legal. A justificativa de morosidade de tomada de decisão pelo Poder Judiciário no Brasil, para realizar o abortamento, fora rechaçada no transcorrer do desenvolvimento do projeto de pesquisa, tendo em vista a precariedade das alegações, porém, a ressalva, para as hipóteses excepcionais, em muitos casos em que a gravidez chegaria ao fim antes do julgamento do caso. Os objetivos específicos foram contemplados, em parte, tendo em vista a ausência de histórico de evolução de decisões sobre o tema, sendo um novo eixo temático na Corte Suprema. Com a abordagem das legislações pertinentes e o debate sobre o tema específico. Os pesquisadores enfocaram com precisão a análise, na íntegra e literal, dos votos do Supremo Tribunal Federal sobre o Aborto de feto anencefálico. O presente estudo foi desenvolvido, por meio de estudos e leitura de material, bibliográfico, normas jurídicas, artigos jurídicos, leis, posicionamentos doutrinários na área de concentração desta pesquisa. Realizamos, periodicamente, encontros e análises de votos de cada Ministros do Supremo Tribunal Federal, expôs as implicações éticas, civis, constitucionais e penais, resultantes da decisão do órgão máximo à respeito do Abortamento de feto de anencéfalo, no desenrolar de cada sessão, partindo-se do desenvolvimento de um 
raciocínio lógico geral, para o particular, utilizando-se o método hipotético dedutivo. Os dados coletados foram confrontados, analisados e interpretados dialeticamente, por meio de método estatístico apto e escolhido por profissional da área, em particular por meio de dados públicos existentes nos sites oficiais dos Tribunais Superiores, em especial, cada voto correlacionado abaixo pelo respectivo Ministro do Supremo Tribunal Federal. Ao final, de forma suscinta, apresenta medidas legais cabíveis de efetivação da decisão do Supremo Tribunal Federal, sem deixar margem à ilegalidade e contribuições para a propositura de políticas públicas regulamentadoras para a efetivação material do aborto de feto anencefálico.

\section{FUNDAMENTAÇÃO TEÓRICA}

Antes de criarmos conceitos próprios sobre algum tema precisamos estudar a respeito, para não nos precipitar em conclusões esdrúxulas. Segundo o Doutor Thomaz Gallop, médico geneticista e professor da Universidade de São Paulo, a anencefalia trata-se do não desenvolvimento da caixa craniana e do encéfalo, o que de fato existe presente é o tronco encefálico, que é a parte superior da medula e fica na região do pescoço. ${ }^{1}$

Nos casos de anencefalia, pela medicina atual, não há métodos de tratamento ou cura que possa viabilizar a vida, a morte do feto é inexorável, inevitável, trata-se de morte cerebral, mesmo que o coração funcione não há vida sem atividade cerebral.

De acordo com a Lei 9434/1997 que dispõe sobre a remoção de órgãos, tecidos e partes do corpo humano para fins de transplante e tratamento, a morte se dá, para todos os efeitos legais, a partir do momento da parada de todas as funções encefálicas, ou seja, ocorrendo a morte cerebral o ordenamento jurídico reconhece a possibilidade de doação dos órgãos.

O feto anencefálico não possui o encéfalo, total ou parcialmente, portanto, não estaria o feto na mesma situação de quem morre com a parada das funções encefálicas. ${ }^{2}$

Cinquenta por cento das mortes em casos de anencefalia são provocadas ainda na vida intrauterina. Dos que nascem com vida, $99 \%$ morrem logo após o parto e o restante pode sobreviver por dias, ou poucos meses. Os que sobrevivem, conseguem fazer o movimento involuntário de engolir, respirar e manter os batimentos cardíacos, já que essas funções são controladas pelo tronco cerebral, a região que não é atingida pela anomalia. Alguns não precisam do auxílio de aparelhos e chegam até a serem levados para casa, mas vivem em estado vegetativo, sem a parte da consciência, que é de responsabilidade do cérebro.

\footnotetext{
${ }^{1}$ GALLOP, Thomaz. Disponível no site: http://noticias.terra.com.br/educacao/vocesabia/noticias/0,,OI5711780-El8399,00.

GOLDIM, José Roberto. Disponível no site: http://noticias.terra.com.br/educacao/vocesabia/noticias/0,0I5711780-El8399,00. Anencefalia+quanto+tempo+e+possivel+sobreviver+sem+cerebro.html.
} 
Diante de tal situação podemos concluir que o feto anencefálico já não possui vida e, sendo o aborto um crime contra a vida, não há que se falar em aborto, não estamos diante de um fato jurídico típico e sim atípico, não se pode proteger a vida de quem já está morto.

O Código Penal prevê apenas duas hipóteses de abortamento, sendo o primeiro o aborto que se faz necessário para salvar a vida da gestante e em segunda hipótese o abortamento de gravidez resultante de estupro. Pois bem, se o feto anencefálico for resultante de estupro não há o que se discutir, pois poderá ser realizado o abortamento pelo fato estupro e não pela anencefalia em si (CONDE, 1988, p. 132).

Segundo Paulo de Tarso Machado Brandão, 'O abortamento consiste, em essência, na morte do concepto antes de sua viabilidade. Quando provocado dolosamente, tipifica o crime de aborto, tratado nos artigos 124 e ss. do Código Penal Brasileiro (CP), Decreto-lei n.o 2.848, de 7 de dezembro de 1940, com a reforma da Lei n.o 7.209, de julho de 1984.' 3

O abortamento é definido como a interrupção da gravidez antes do termo normal, com morte do embrião, sendo indiferente sua expulsão ou não, assim como a viabilidade do produto sobre o qual incidem as manobras. Para Coutinho (2007, p. 10), o alerta que nos casos de anencefalia a gravidez é uma situação muito desejada, não é uma situação em que a mulher desejasse, a priori, interromper a gravidez, o diagnostico do infortúnio de uma anomalia fetal é que leva a essa decisão extremamente traumática, tampouco reservada há uma estrita previsão normativa.

A doutrina das justificativas supralegais funda-se na afirmação de que o direito do Estado, por ser estático, não esgota a totalidade das possibilidades de previsão legal, sendo impossível esgotar todas as causas de justificação da conduta humana no plano da vida social. Partindo-se desta premissa pode-se afirmar antijuricidade nada mais é do que a lesão de determinado interesse vital aferido perante as normas de cultura reconhecidas pela sociedade, sendo assim, afirma-se que não se deve apreciar o antijurídico apenas diante do direito legislado, mas também das normas de cultura. Além do que o legislador não é o onisciente, não lhe sendo dado o dom de prever todas as hipóteses e casos que a vida social possa apresentar nos domínios do Direito Penal [...]. Os defensores dessa linha de pensamento justificam seu entendimento na parte da doutrina que admite a exclusão da culpabilidade.

Entretanto, no caso de ser necessário para salvar a vida da gestante podemos incluir, de forma análoga, o abortamento de feto anencefálico, pois futuramente poderá trazer riscos para a vida da gestante, porque o feto anencefálico não engole o liquido da bolsa, também conhecido como liquido amniótico, como fetos normais, com isso o liquido amniótico se acumula e forma o 
que os médicos chamam de polihidrâmnio, causando a distensão exagerada do útero que poderá deixar de se contrair, não voltando ao formato considerado normal, e condicionando a enormes hemorragias. Não traz riscos imediatos à gestante, mas devemos considerar todos os riscos a ela inerentes, de maneira a garantir sua integridade física e moral. O feto anencefálico é considerado morto, tanto pela legislação quanto pela medicina e não há que se falar na ofensa do principio da dignidade humana do feto. O diagnóstico é preciso para esses casos, em qualquer hospital do Brasil, seja da rede pública ou privada, que possua exame de ultrassonografia (VIEIRA, 2004, p. 32).

A recente decisão do S.T.F. (Supremo Tribunal Federal), na ADPF-54 (Arguição de Descumprimento de Preceito Fundamental de número 54), que julgou procedente o aborto nos casos de anencefalia, gerou muita polemica pelo fato de não se conhecer o assunto claramente, entendendo-se que, se o feto anencefálico morre poucos minutos após o seu nascimento significa que tem vida, pois para morrer é preciso estar vivo, esse foi um dos fundamentos usado pelo Ministro Cezar Peluso, que foi contra o aborto de anencefálico, de certa forma tem razão o Ministro, porém, como já foi dito, nosso ordenamento jurídico estabelece na lei 9434/97 que dispõe sobre a remoção de órgãos, tecidos e partes do corpo humano, que é reconhecida a morte quando há parada de todas as funções encefálicas, houve aqui equivoco do Ministro a respeito do momento em que ocorre o óbito.

O reconhecido o direito de realizar o abortamento ficou vago, pois a única exigência é que se tenha um laudo médico comprovando a anomalia, deixando a critério do médico e da vontade da mãe a realização de tal procedimento (CAMPOS, 1988, p.21).

Aborto, se realizado de forma arbitrária, e sem justificativa excludente de ilicitude é considerado crime, mas aqui vem à importância de se pensar na decisão do Supremo, ter um falso laudo médico, atestando a anomalia encefálica é teoricamente fácil, qualquer gestante, com dinheiro e vontade consegue, o que deixa liberdade para acontecer crimes de aborto sem qualquer controle, derrubando princípios éticos, civis, constitucionais e penais.

Segundo Luiz Flávio Gomes (Revista Síntese de Direito Penal e Processual Penal. Ano V. N.o 28- Out-Nov 2004. p. 35 e 36)

Os que sustentam (ainda que com muita boa-fé) o respeito à vida do feto devem atentar para o seguinte: em jogo está a vida ou a qualidade de vida de todas as pessoas envolvidas com o feto mal formado. E até em caso de estupro, em que o feto está bem formado, nosso Direito autoriza o aborto, nada justifica que idêntica regra não seja estendida para o aborto anencefálico. Lógico que a gestante, por suas convicções religiosas, pode não querer o aborto. Mas isso constitui uma decisão eminentemente pessoal (que deve ser respeitada). De 
qualquer maneira, não se pode impedir o exercício do direito ao abortamento para aquelas que não querem padecer tanto sofrimento.

Nas sustentações orais também tivemos várias opiniões como o que segue, no Congresso Nacional e no Senado Federal. ${ }^{4}$

O Estado deve estabelecer formas de controle para que seja realizado o abortamento de anencefálico, com a previsão legislativa, e, principalmente a atribuição aos órgãos reguladores e fiscalizadores, para tal feito.

\section{CONCLUSÃO}

Os resultados vislumbraram a importância em discutir a temática proposta, frente ao problema na efetivação da decisão do Supremo Tribunal Federal. Durante a votação os ministros Celso de Mello e Gilmar Mendes, em síntese, queriam que fosse incluída a necessidade de diagnóstico de anencefalia por dois médicos desconhecidos da paciente para que a interrupção da gravidez pudesse ser feita, mas a tese foi recusada. Também foi recusada a inclusão do termo "comprovadamente anencéfalo", na proclamação pela Colenda Corte Suprema. Como se vê, alguns Ministros já demonstraram preocupação com o tema, porém, a tese levantada durante a votação foi recusada pela maioria com a justificativa de que cabe ao Legislativo, a criação e regulamentação das Leis.

A importância acadêmica e científica do presente estudo contribui para reflexão junto à comunidade acadêmica, no sentido de despertar o interesse e a participação mais efetiva nas discussões, ensejando inclusive em resultados, como do presente projeto. A realização do tema proposto viabilizou-se pela disponibilidade dos votos on-line e de domínio público, o que propiciou um material vasto para análise de cada voto, de forma pormenorizada, finalizando nas conclusivas de ordem prática. Por todo o exposto, o Supremo Tribunal Federal acertou em sua decisão, descriminalizando a antecipação terapêutica do parto nos casos de anencefalia, porém, deixou a cargo do Legislativo a elaboração de normas que estabeleçam os meios legais para que o procedimento seja realizado sem deixar margem a erros. Vale ressaltar que, nesse caso deve o mesmo ser acompanhado da fiscalização do Estado, mesmo que o Ministério Público não tenha entendimento do diagnóstico, este poderia garantir a autenticidade do mesmo, servindo como um fiscal nesses casos, para que não aconteçam abortos ilegais.

\footnotetext{
${ }^{4}$ Deputada Jandira Feghali (PCdoB-RJ) http://www.abortoemdebate.com.br/wordpress/ "Pela importância do tema e em reconhecimento à brilhante argumentação do relator, solicito o registro deste voto nos anais desta Casa. Espero que a Câmara dos Deputados tome conhecimento dos argumentos apresentados à Suprema Corte e avance garantindo, em Lei, a possibilidade do aborto em casos de anencefalia." e Soninha Francine pré-candidata do PPS à prefeitura de São Paulo http://www.abortoemdebate.com.br/wordpress.
} 


\section{REFERENCIAS}

BRANDÃO, Paulo de Tarso Machado, Aspectos Jurídicos Controversos no Crime de Abortamento, 1993. p. 10.

FÁVERO, Flamínio. Medicina Legal. 2 ed. Belo Horizonte: Editora Vila Rica, 1991. p. 23.

CONDE, Francisco Muñoz, Teoria Geral do Delito - Tradução de Juarez Tavares e Luiz Regis Prado. Porto Alegre: Sérgio Antonio Fabris Editor, 1988, p. 132.

VIERA, Tereza Rodrigues. Aborto por Anencefalia Fetal e o Direito Atual. Ano VIII - no. 174. Revista Jurídica Consulex. Brasília: Consulex, 2004. p. 32.

CAMPOS, João Mendes. A Inexigibilidade de Outra Conduta no Júri: Doutrina e Jurisprudência. Belo Horizonte: Del Rey, 1998. p. 21

Revista Síntese de Direito Penal e Processual Penal. Ano V. N. 28- Out-Nov 2004. p. 35 e 36., de Luiz Flávio Gomes.

SAVARESE , Maurício, Do UOL, em Brasília - 17/04/2012

COUTINHO, Luiz Augusto, Aborto nos caos de anencefalia: crime ou inexigibilidade de conduta diversa. Disponível no site: http://www.buscalegis.ufsc.br/arquivos/aborto_anencefalia_1703.htm (Acesso em: 10/10/2007, p.10) e http://noticias.uol.com.br/ciencia/ultimasnoticias/redacao/2012/04/12/supremo-aprova-antecipacao-de-parto-de-feto-anencefalo.htm.

GALLOP, Thomaz. Disponível no site:

http://noticias.terra.com.br/educacao/vocesabia/noticias/0,0l5711780-El8399,00.

Anencefalia+quanto+tempo+e+possivel+sobreviver+sem+cerebro.html.

GOLDIM, José Roberto. Disponível no site:

http://noticias.terra.com.br/educacao/vocesabia/noticias/0,015711780-El8399,00.

Anencefalia+quanto+tempo+e+possivel+sobreviver+sem+cerebro.html

Deputada Jandira Feghali (PCdoB-RJ) http://www.abortoemdebate.com.br/wordpress/

Soninha Francine pré-candidata do PPS à prefeitura de São Paulo

http://www.abortoemdebate.com.br/wordpress. 